\title{
THE AWARENESS OF BARODONTALGIA AMONG DENTAL STUDENTS
}

\author{
Ebtissam Al-Madi ${ }^{*}$, Alaa Al-Harbi ${ }^{* *}$, Alaa Al-Obeid, ${ }^{* * *}$ Fatin Al-Aqil, ${ }^{* * * *}$ \\ Samar A. Al-Saleh, ${ }^{* * * * *}$ and Mohammad I. Al-Obaida*
}

\begin{abstract}
Objective: Barodontalgia is dental pain provoked by atmospheric pressure changes. The incidence is high in the Arabian Gulf region (34\% in divers and pilots). The aim of the study was to measure students' knowledge about barodontalgia.
\end{abstract}

Methods: 1110 questionnaires consisting of knowledge of barodontalgia (definition, diagnosis, treatment, and prevention) were distributed among dental students in three dental schools in Saudi Arabia.

Results: The response rate was $75 \%$. Only $22.2 \%$ were aware of the correct definition of barodontalgia. Most students did not know the correct answers to questions about Barodontalgia $(57-70 \%) .80 .4 \%$ of the students indicated that they did not have any formal education in relation to barodontalgia. $3.2 \%$ of students were exposed to a case of barodontalgia during their clinical studies. Most of the students $(82 \%)$ were interested to know more about barodontalgia.

Conclusion: There is low awareness of Barodontalgia among students. Dental curricula should include knowledge of this phenomenon.

KEYWORDS: Barodontalgia; Dental Undergraduate Students; Dental Curriculum; Dental Pain.

\section{INTRODUCTION}

With the increasing number of airline passengers, pilots, military aircrews, professional and leisure divers; dentists may encounter related oral conditions that require immediate treatment
(Lakshmi \& Sakthi, 2014). Barodontalgia is dental pain, commonly confused with irreversible pulpitis, which is provoked by atmospheric pressure changes, which usually disappears when the affected person returns to normal pressure zone (AlHajri \& AlMadi, 2006). Other phenomena include dental barotrauma;

\footnotetext{
* Department of Restorative Dental Sciences, College of Dentistry, King Saud University, Saudi Arabia

** King Fahad Military Hospital, Dhahran, Saudi Arabia

*** King Abdulaziz Medical City National Guard Health Affairs, Riyadh, Saudi Arabia

**** Prince Sultan Medical City Hospital, Riyadh, Saudi Arabia

***** Department of Prosthetic Dental Sciences, College of Dentistry, King Saud University
} 
which is barometric pressure-induced tooth and restoration fracture, as well as reduced retention of a restoration (Zadik et al., 2006). Barotrauma is a condition caused by a difference in pressure between the body and the surrounding fluid. It can occur during flying, diving, or hyperbaric oxygen therapy. It involves conditions like external otitic barotrauma, barotitis-media, barosinusitis, barotrauma-related headaches, dental barotrauma, and barodontalgia (Lakshmi \& Sakthi, 2014).

The incidence of barodontalgia is not uncommon (AlHajri \& AlMadi 2006). However, variations in prevalence have been reported in different populations. Barodontalgia prevalence is particularly high in the Arabian Gulf region. AlHajri and AlMadi in 2006 reported that 34\% of military pilots and divers from Saudi Arabia and Kuwait experienced barodontalgia at one point in time during their career (AlHajri \& AlMadi, 2006).

Dentists should be prepared to identify, evaluate and manage such cases, and also take preventive measures as well as periodically examine patients susceptible to barodontalgia (pilots and scuba divers) (Zadik, 2009). Unfortunately, such awareness does not exist. Although there is $61.1 \%$ knowledge of barodontalgia among general dentists in the form of correct recognition of the word and definition, on the other hand; less than $28 \%$ could identify at least one group affected by the phenomenon (AlMadi, 2010). We therefore hypothesize that there is limited awareness regarding Barodontalgia. The aim of this study was to evaluate dental students' awareness of barodontalgia.

\section{MATERIALS AND METHODS}

The Institutional Review Board of the College of Dentistry, King Saud University has deemed the study exempted from full review, and thus has approved the study prior to its commencement. All students enrolled in the current academic year of three dental colleges in Saudi Arabia; two in Riyadh and one in Dammam were included in the study. Excluded were preparatory year students and dental interns. The total number of students sampled was 1110 (590 to KSUCD, 400 to REUCD, and 110 to AIUCD).

A structured questionnaire designed to determine the knowledge of students of the topic of barodontalgia. Eight different questions were designed in relation to knowledge regarding the definition, the population affected, etiology, diagnosis, prevention, importance, treatment and treatment providers for barodontalgia. Content validation was determined by reviewing these questions with 3 experts in the field. The knowledge-based questions were followed by questions to determine source of knowledge, actual clinical exposure to a case and need for additional knowledge. A final open-ended comment was left for students to present their opinions. The knowledge-based questions were multiple choice answers with one correct answer, 2 distractors, and "I don't know" (table 1). The questionnaire also requested demographic data: gender, age, school, level, and GPA. Validation of the questionnaire was performed through a pilot study with a sample of 25. The questionnaires were distributed immediately after one of the lectures to all dental students present in their classes in the school on the day the questionnaire was distributed, so that a maximum number of responses would be retrieved. Students were requested not to discuss the questions with their colleagues or search the answers with their mobile devices. The students were assured of anonymity and confidentiality and that their participation is voluntary and would not have any consequences if they choose not to participate.

Data was entered into SPSS version 16 and analyzed. Descriptive analysis and Chi-square analysis were used cross tabulating gender, level and GPA with correct, incorrect and "I don't know" answers. The open-ended comments were evaluated, coded and grouped for qualitative data analysis. 


\section{RESULTS}

A total of questionnaires were returned $(75 \%$ overall response rate), with KSUCD $85 \%$, REUCD $65 \%$, and AIUCD 82\%. There were $521(62.6 \%)$ male respondents and $311(37.4 \%)$ female respondents. Overall approximately $22 \%$ of students had a sufficient knowledgeable about barodontalgia. Table 1 shows the percentage of students who answered correctly for each question category. Fifth year students (final year) in all colleges had the highest percentage of correct answers (36.3\%), while 1 st year students had the lowest percentage $(5.3 \%)(\mathrm{p}=0.000)$. Fourth year students had fewer correct answers compared to 3rd and 2nd year students, though not significantly less.

Female students were aware of the causes of barodontalgia and the method of which barodontalgia can be diagnosed significantly more than their male counterparts ( $\mathrm{p}=0.006, \mathrm{p}=0.000$ ) (fig. 1 ). There was no correlation between GPA and correct answers.

Many of the students chose the answer; "I don't know". $80.4 \%$ reported that they were not formally taught about barodontalgia. Only $8.3 \%$ said they learned about it from a lecture, $9.1 \%$ from personal reading, and $2.2 \%$ from a textbook. There were no significant differences between gender, age, dental school or year.

Only $3.24 \%$ were exposed to a case of barodontalgia, all of which were male students and mostly in the second and third years. Their exposure was in the Oral Medicine clinics of their respective colleges ( 8 cases), and the remainder seen were during the summer training courses.

Eighty-two per cent of the students were interested to learn more about barodontalgia, regardless of their gender, age, dental school, year or GPA.

Specific responses were categorized into 3 groups; those who have never heard of the term; "Why I am in fourth year and I don't know it?" $(61.5 \%)$, those who were guessing at the topic: "Is it related to irreversible pulpitis?" (4.6\%), and those who wanted to learn more "We need more information about barodontalgia" (33.8\%).

TABLE (1): Percentage of students whom answered correctly for each question distributed by gender, level and GPA. $*(\mathrm{p}<0.05)$

\begin{tabular}{|c|c|c|c|c|c|c|c|c|c|c|}
\hline \multirow{3}{*}{ Gender } & Male & 34 & 30 & $9.4^{*}$ & $12.1 *$ & 22.6 & 12.3 & 23.4 & 16.9 & 20 \\
\hline & Female & 40.5 & 38.9 & $15.8^{*}$ & $23.8 *$ & 21.5 & 16.1 & 23.2 & 15.4 & 24.4 \\
\hline & Ave & 37.3 & 34.5 & 12.6 & 18 & 22 & 14.2 & 23.3 & 16 & 22.2 \\
\hline \multirow{5}{*}{ Level } & $1^{\text {st }}$ year & $6.1^{*}$ & $3.1 *$ & $6.1^{*}$ & $6.9^{*}$ & $3.1^{*}$ & $3.8^{*}$ & $5.3^{*}$ & $8 *$ & 5.3 \\
\hline & $2^{\text {nd }}$ year & 39.5 & 36.5 & 13.8 & 9.6 & 12 & 13.8 & 16.8 & 7.2 & 18.6 \\
\hline & $3^{\text {rd }}$ year & 41.7 & 39.6 & 14.4 & 22.5 & 25.1 & 17.1 & 28.3 & 19.8 & 26 \\
\hline & $4^{\text {th }}$ year & 29.3 & 26.9 & 10.8 & 12.6 & 21.6 & 10.2 & 16.8 & 15.6 & 18 \\
\hline & $5^{\text {th }}$ year & 56.7 & 53.9 & 12.2 & 27.2 & 43.3 & 20.6 & 43.3 & 33.3 & 36.3 \\
\hline \multirow{5}{*}{ GPA } & $2-3$ or $<$ & 56.5 & 58 & 14.5 & 5.8 & 56.5 & 23.2 & 30 & 43.5 & 36 \\
\hline & $>3-3.5$ & 32.4 & 26.7 & 8 & 15.9 & 19.9 & 10.8 & 39.8 & 14.8 & 21 \\
\hline & $>3.5-4$ & 33.5 & 32.1 & 12.2 & 16.3 & 20.4 & 11.8 & 50 & 11.3 & 23.4 \\
\hline & $>4-4.5$ & 31.8 & 29 & 11.1 & 17.5 & 17.1 & 12.4 & 26.7 & 12 & 19.7 \\
\hline & $>4.5$ & 43.5 & 40.8 & 15.6 & 20.4 & 19 & 17 & 40.1 & 18.4 & 26.8 \\
\hline
\end{tabular}




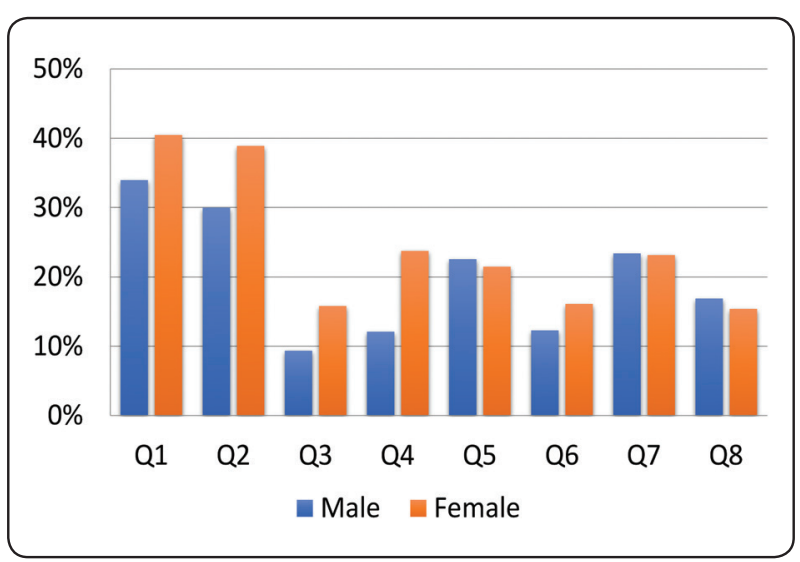

Fig. (1) Responses of Female students compared to male students

\section{DISCUSSION}

This study was conducted to evaluate the knowledge of barodontalgia among dental students. Not much is known about the amount of awareness of the condition therefore, preliminary data was essential to evaluate and take necessary step to augment any gaps in knowledge to be addressed at curriculum committee evaluations.

There was generally low knowledge of barodontalgia among all students. An average of $22.2 \%$ of students answered questions regarding barodontalgia correctly. Students were most knowledgeable about the definition of barodontalgia (37.3\%) followed by knowledge of the groups affected by it $(34.5 \%)$, the treatment necessary $(23.3 \%)$, prevention of barodontalgia $(22 \%)$, diagnosis $(18 \%)$, treatment provider $(16 \%)$, importance of recognition (14.2\%) and least knowledgeable about cause of barodontalagia (12.6\%). Little knowledge about the cause of barodontalgia is quite alarming. The fifth-year students (final year) had the highest percentage of correct answers, while the 1st year students had a significantly smaller number of correct answers in all categories $(p=0.000)$. This seem to be related advancement in stage and year, or through personal knowledge (elective reading or personal review); exposure to cases (patients with barodontalgia), increased maturity, and preparation for licensing exams. On the other hand, second- and third-year students performed better than fourth year students, mainly because barodontalgia might be seen in oral medicine clinics that are primarily attended in the second and third years of studies. The pattern of knowledge in all five years was consistent with the general trend (knowledge of definition and affected group most, then by prevention and treatment, followed by the other aspects).

Only minor insignificant differences between the three dental schools were found, which might be attributed to different curricula used, that may or may not have intended learning outcomes that are directly related to knowledge about barodontalgia.

GPA levels showed no correlation to the study. This indicates that the awareness of the condition does not depend on study, or scholastic achievement, as most likely students were never formally exposed to the topic. Although insignificant; it was odd to find that lower GPA students answered correctly in questions related to diagnosis, affected group, prevention, importance and treatment provider. This could accentuate the assumption that the topic might not be formally addressed in courses.

Results of the investigation showed that only $3.24 \%$ of dental students (males) had been exposed to cases of barodontalgia. Most affected groups of patients (mainly pilots and divers) are commonly male. In addition, most of these cases were seen in summer training sessions, and it is expected that dental clinics offering services to pilots and divers are in military or naval centers that are serviced by male dentists. On the other hand, male students had significantly less correct answers compared to female students regarding cause and diagnosis of barodontalgia (Fig 1). Some studies have discussed the possible reasons why Jordanian female students might outperform male dental students (Sawair, Baqain et al. 2009), which might also be applicable 
to Saudi students. These factors include that acceptance grades to enroll in dental schools is very competitive among females, as more females might prefer dentistry as a profession. Therefore, female students entering dental colleges have higher GPA's than male students. In addition, the workforce is more competitive for females, as they prefer to work in the same area they studied, while male are more mobile, therefore, their awareness of this competitiveness challenges them to achieve higher grades. Dental curriculum committees need to adequately correlate exposure to this phenomenon and learning outcomes and capitalize on the possibility of exposure to this phenomenon in clinics for male students and compensate lack of exposure for female students.

Barodontalgia is a phenomenon that should not be dismissed as unimportant, as it can pose a serious safety risk to divers, pilots and airline passengers (Robichaud \& McNally, 2005). Since this condition is commonly mistaken for endodontic involvement of teeth, it should be adequately clarified to students. Unfortunately, questions regarding importance of recognition of barodontalgia was answered least correctly among students (14.2\%). Prevalence is significant worldwide, one investigation reported prevalence at $17.3 \%$ among divers (Zadik \& Drucker, 2011), while another reported an $8 \%$ prevalence in aviation (Lakshmi \& Sakthi, 2014). Among French Armed Forces, 7.3\% of examined individuals suffered from at least one episode of barodontalgia (Gunepin et al., 2016), as compared to a $6.5 \%$ in French civilians, military pilots and aircrew experienced (Laval-Meunier et al., 2013). In a Spanish population it was 2.63\% (Del Mar Gonzales Santiago et al., 2004) and among Indian pilots it was $20.6 \%$ (Rai et al., 2010). The variations in prevalence might be due to differences in the regulations in oral health evaluation prior to flying or diving. Barodontalgia prevalence is particularly high in the Arabian Gulf region. AlHajri and AlMadi in 2006 reported that $34 \%$ of military pilots and divers from Saudi Arabia and Kuwait experienced barodontalgia at one point in time during their career (Al Hajri \& AlMadi, 2006). As the incidence of barodontalgia is high in the gulf region, dental students should be aware of this phenomenon. It is therefore recommended that dental students should encounter more information through their study in dental colleges.

Recent literature showed that no studies have been published regarding knowledge of dental students of the term, therefore it was difficult to compare studies. Data reported by Al-Madi (2010) show that only $61.1 \%$ of general dentists could correctly define the meaning of the term barodontalgia, on the other hand; less than $28 \%$ could identify at least one group affected by the phenomenon (AlMadi, 2010). In general, dental students were significantly less able to know the definition of the term $(22.2 \%)$, although final year dental students were more able to recognize the term $(56.7 \%)$. Several studies showed that barodontalgia may go unnoticed due to negligence (Laval-Meunier et al., 2013; Del Mar Gonzales Santiago et al., 2004). It is important to clearly identify areas of knowledge gaps within students and general dentists and co-relate that with the presence of the phenomenon in a population to adequately address all needs of the society. Clearly, barodontalgia is a relatively prevalent occurrence within the society that must be adequately addressed in dental curricula.

\section{CONCLUSION}

The data showed that there was low percentage of general knowledge regarding barodontalgia (22.2\%) among dental students. Barodontalgia is a phenomenon that should not be dismissed as unimportant, as it can pose a serious safety risk to divers, pilots and airline passengers. It is therefore recommended that dental schools highlight this topic and incorporate the diagnosis, recognition, prevention, and treatment of barodontalgia as a 
topic within their curriculums, so that students will be better prepared to handle cases adequately.

\section{REFERENCES}

1 AlHajri W, AlMadi E. Prevalence of barodontalgia among pilots and divers in Saudi Arabia and Kuwait. Saudi Dent J 2006;18 134-140.

2 AlMadi EM. Knowledge about Barodontalgia among dentist in Saudi Arabia. Egypt Dent J 2010; 56:2331-2339.

3 Del Mar González Santiago M, Martinez-Sahuquillo Marquez A, Bullón Fernández P. Incidence of barodontalgias and their relation to oral/dental condition in personnel with responsibility in military flight. Med Oral 2004; 9: 92-105.

4 Gunepin M, Derache F, Blatteau JE, Nakdimon I, Zadik Y. Incidence and features of barodontalgia among military divers. Aerosp Med Hum Perform 2016;87: 137-140.

5 Lakshmi D, Sakthi DS. Aviation dentistry. J Clin Diag Res 2014; 8:288-290.

6 Laval-Meunier F, Bertran PE, Arrive E, Paris JF, Monteil M, Nguyen S. Frequency of barodontalgia among military or civilian pilots and aircrew members. Aviat Space Environ Med 2013; 84:1055-1060.

7 Rai B, Kaur J, Catalina M, Anand SC. Prevalence of barodontalgia in Indian origin pilots: a survey. Int J Stomatol Occlusion Med 2010; 3:115-117.

8 Robichaud R, McNally ME. Barodontalgia as a differential diagnosis: symptoms and findings. J Can Dent Assoc 2005; 71:39-42.

9 Sawair, F. A., Z. H. Baqain, I. K. Al-Omari, F. K. Wahab and L. D. Rajab (2009). "Effect of gender on performance of undergraduate dental students at the University of Jordan, Amman." Journal of dental education 73(11): 1313-1319.

10 Zadik Y, Einy S, Pokroy R, Bar Dayan Y, Goldstein L. Dental fractures on acute exposure to high altitude. Aviat Space Environ Med 2006; 77:654-657.

11 Zadik Y. Aviation dentistry: current concepts and practice. Br Dent J 2009; 206:11-16.

12 Zadik Y, Drucker S. Diving dentistry: a review of the dental implications of scuba diving. Aust Dent J 2011; 56:265-271. 